\title{
Fox-Fordyce disease: report of two cases with perifollicular xanthomatosis on histological image
}

\author{
María Elisa Vega-Memije, Diego Olin Pérez-Rojas², Leticia Boeta-Ángeles ${ }^{3}$, Patricia Valdés-Landrum
}

DOI: http:/ / dx.doi.org/10.1590/abd1806-4841.20187475

\begin{abstract}
Fox-Fordyce disease is a relatively infrequent pathology of the apocrine glands that affects almost exclusively young women. The disease is characterized by the presence of pruritic follicular papules mainly in the armpits that respond poorly to treatment and severely affect the patient's quality of life. We report two cases with clinical diagnosis and histopathological confirmation, presenting perifollicular xanthomatosis on histological examination, recently described as a distinctive, consistent, and specific feature of this disease.
\end{abstract}

Keywords: Apocrine glands; Fox-Fordyce disease; Miliaria

\section{INTRODUCTION}

Fox-Fordyce disease (FFD), also known as apocrine miliaria or chronic pruritic papular eruption of the pubis and armpits, affects areas where apocrine glands are found predominantly, such as the pubic, axillary, and anogenital regions. ${ }^{1,2}$ The pathogenesis remains unknown, and the disease affects primarily young women. ${ }^{3}$ Commonly used treatments are poorly or partially effective, as the lesions frequently recur and the symptoms persist.

We present two cases with both clinical and histopathological diagnosis of perifollicular xanthomatosis.

\section{CASE REPORTS}

\section{CASE 1}

A 33-year-old female patient, resident of Mexico City, previously healthy, reported a one-month history of multiple mildly pruritic papules in both armpits. Patient reported hyperhidrosis and no prior treatment.
Physical examination showed localized, bilateral, asymmetric alterations affecting both axillae, more prominently on the left, characterized by yellowish-brown punctate papules $1 \mathrm{~mm}$ in diameter with a smooth uniform surface and follicular distribution (Figure 1).

Histopathological examination with H\&E staining showed dilation of the follicular infundibulum with corneal plug, as well as inflammatory lymphohistiocytic infiltrate with xanthomatous cells surrounding the infundibulum (Figure 2). Intrafollicular and apocrine gland mucin deposits were observed with Alcian blue staining.

Immunohistochemistry showed perifollicular cells strongly positive for CD68. Carcinoembryonic antigen and epithelial membrane antigen were negative in the xanthomatous cells (Figure 3).

FFD was confirmed and topical clindamycin was initiated, with improvement of the symptoms.

\footnotetext{
$\overline{\text { Received } 18 \text { August } 2017 .}$

Accepted 03 November 2017.

* Work conducted at the "Dr. Manuel Gea González" General Hospital, Mexico City, Mexico.

Financial Support: None.

Conflict of Interest: None.

Dermatopathology Department, Dr. Manuel Gea González General Hospital - Mexico City, Mexico.

Internal Medicine, Universidad Nacional Autónoma de México (UNAM) - Mexico City, Mexico.

Dermatology Department, Juárez Centro Hospital - Mexico City, Mexico.

Clínica Dermatológica Valdés - León, Guanajuato, Mexico.
}

\section{MAILING ADDRESS:}

Diego Olin Pérez-Rojas

E-mail: diegoolinperezrojas@gmail.com

C2018 by Anais Brasileiros de Dermatologia 


\section{CASE 2}

A 24-year-old female patient, resident of León, Guanajuato, Mexico, presented intensely pruritic papules in both armpits and the genital area with two years' evolution. Patient had received pri-

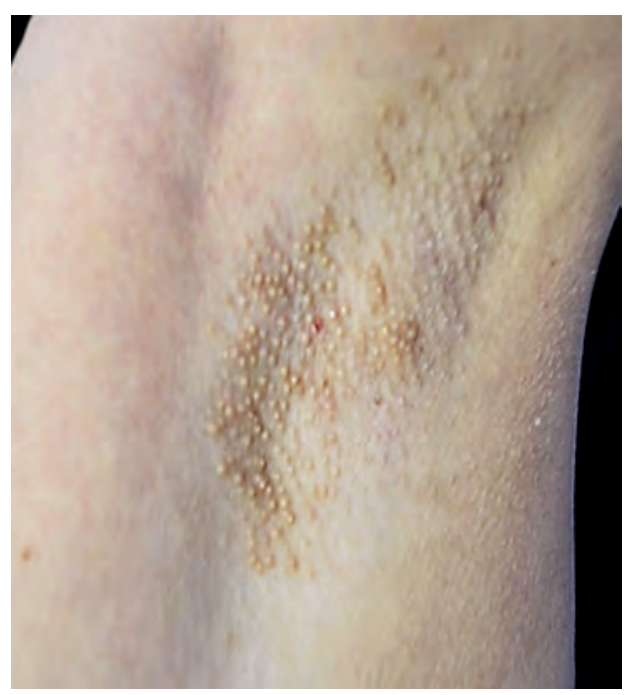

Figure 1: Fox-Fordyce Disease. Case 1. Yellowish-brown punctate papules with follicular distribution coalescing in plaques and affecting both armpits

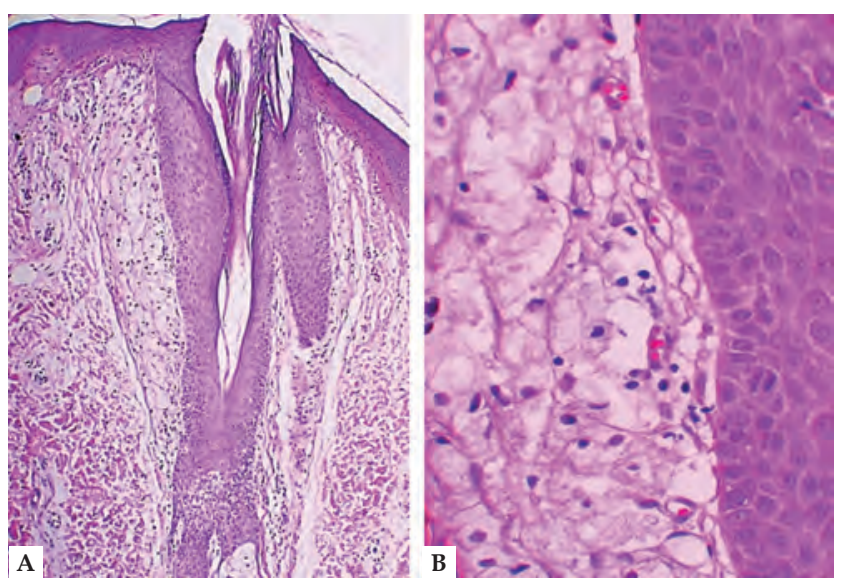

Figure 2: Fox-Fordyce Disease. A. Histological section with infundibular dilation and corneal plug (Hematoxylin \& eosin, x10) B. Higher magnification of xanthomatous peri-infundibular cells (Hematoxylin \& eosin, $x 40$ ) or treatment with antihistamines and emollients with no improvement. Patient reported that other females in her family had presented this skin condition in the armpits, although less severe.

Patient had a 12-year history of comedogenic acne on the face and trunk as well as menstrual alterations with amenorrhea of up to 2 months. Therefore, pelvic ultrasound was ordered, showing polycystic ovaries.

Physical examination showed a disseminated dermatological condition affecting the axillae and genitalia, in hairy areas, characterized by skin-colored punctate papules 1 to $2 \mathrm{~mm}$ in diameter with follicular distribution and some crusts (Figure 4).

Histopathology showed dilated follicular infundibula with hyperkeratosis, as well as xanthomatous histiocytes with perifollicular distribution and discrete inflammatory lymphocytic infiltrate. Intrafollicular mucin deposits were also observed (Figure 5).

FFD was diagnosed, and combined oral contraceptives (cyproterone with ethinylestradiol) and topical hydrocortisone were prescribed, with partial improvement of lesions and pruritus.

\section{DISCUSSION}

Fox-Fordyce disease was first described in 1902 by American authors George Henry Fox and John Addison Fordyce. ${ }^{1,2}$ The pathogenesis of this condition remains unknown, although proposed theories suggest that hormonal factors, hair removal, and inheritance may be involved in the apocrine obstruction, sweat retention, and inflammation., ${ }^{3,4}$

This disease entity presents characteristic clinical data, affecting areas of the body where apocrine glands are found, such as armpits, pubis, and the anogenital region. However, less frequent locations on the thorax, areolas, abdomen, and legs have been described. ${ }^{5}$ The disease occurs mainly in women 15 to 35 years of age and usually remits in menopause. ${ }^{6}$ In the current cases, we report typical lesions affecting the axillary region and genitals, with no lesions on other parts of the body surface. Both patients were childbearing-age women.

Clinically, FFD is characterized by the presence of multiple skin-colored follicular papules, slightly yellowish or brown, domeshaped, with a smooth surface, which may be accompanied by mild to moderate pruritus or even be asymptomatic. Exacerbating symptoms include heat, moisture, physical activity, friction with clothing, and excessive sweating. ${ }^{7}$ Laser hair removal and intense pulsed light have also been described as triggers. ${ }^{4,8}$ The lesions tend to dis-
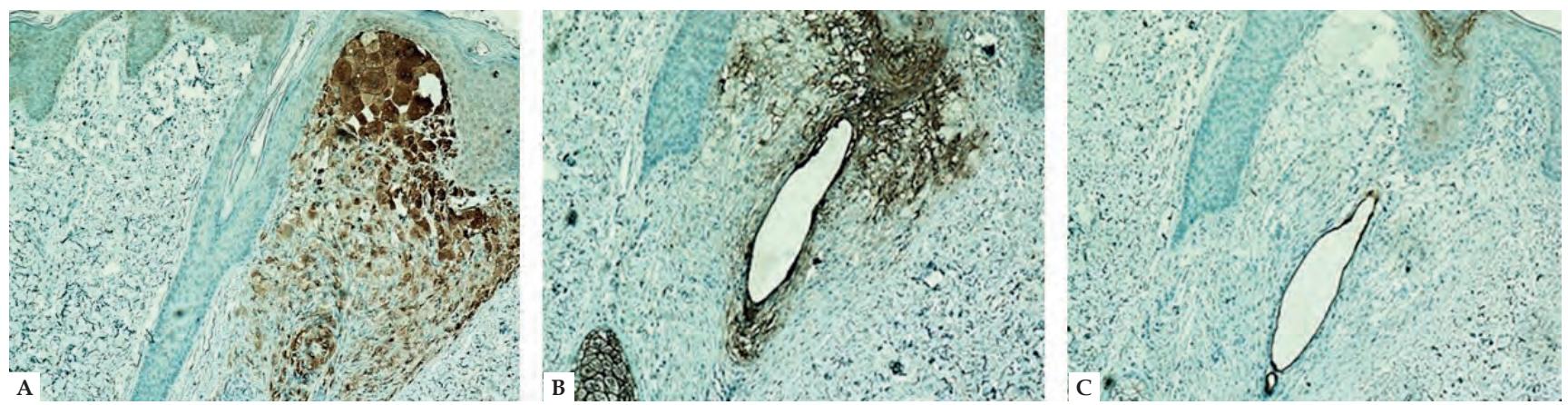

FiguRE 3: Fox-Fordyce Disease. Immunohistochemistry. A - CD68 intensely positive in peripheral xanthomatous histiocytes. B - Negative membrane epithelial antigen $\mathbf{C}$ - Negative carcinoembryonic antigen in histiocytes 


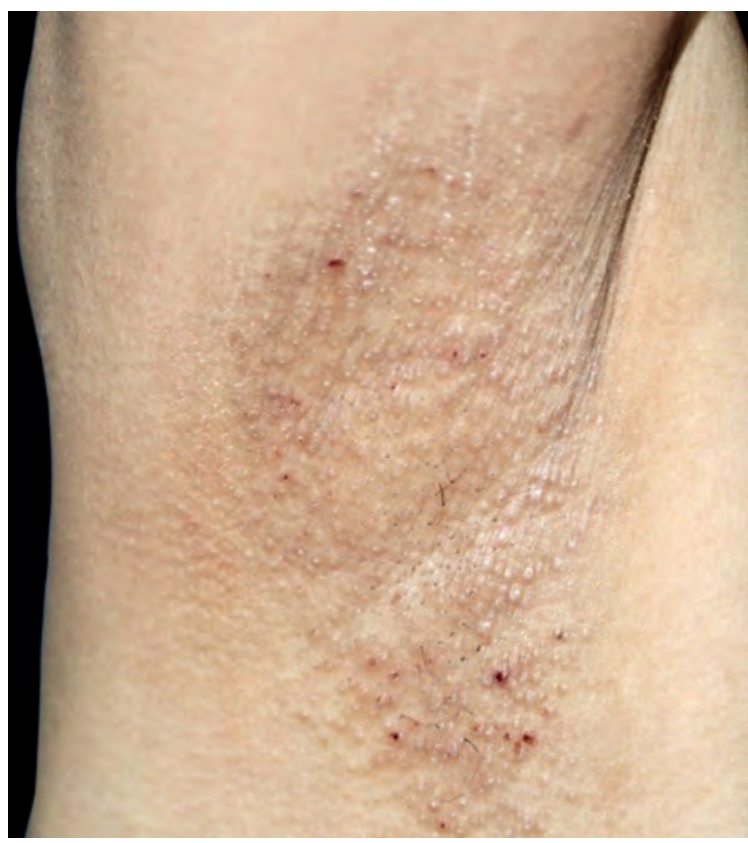

Figure 4: Fox-Fordyce Disease. Case 2. Punctate papules with follicular distribution in the armpits and hemorrhagic crusts due to scratching

play chronic evolution, described as lasting weeks to years. ${ }^{7}$

Differential diagnoses include Graham-Little-Piccardi-Lasseur syndrome, trichostasis spinulosa, Darier's disease, syringomas, lichen nitidus, lichen amyloid, and papular mucinosis.,10

Definitive diagnosis is made by histopathological examination in which nonspecific findings such as intrafollicular corneal plug, hyperkeratosis, spongiosis, retention vesicles, glandular dilation with mucin deposits, and perifollicular lymphohistiocytic inflammatory infiltrate can be observed..$^{11,12}$ The presence of infundibular dyskeratotic cells, vacuolar changes, and parakeratosis similar to cornoid lamella have also been described. ${ }^{13}$ However, Bormate et al. recently described the presence of foamy or xanthomatous histiocytes (perifollicular xanthomatosis) as a distinctive, consistent, and more specific feature of this pathology. ${ }^{13}$ This was corroborated in the histopathology of our cases, as both presented the previously described findings and xanthomatous histiocytes as well as the presence of intrafollicular mucin.
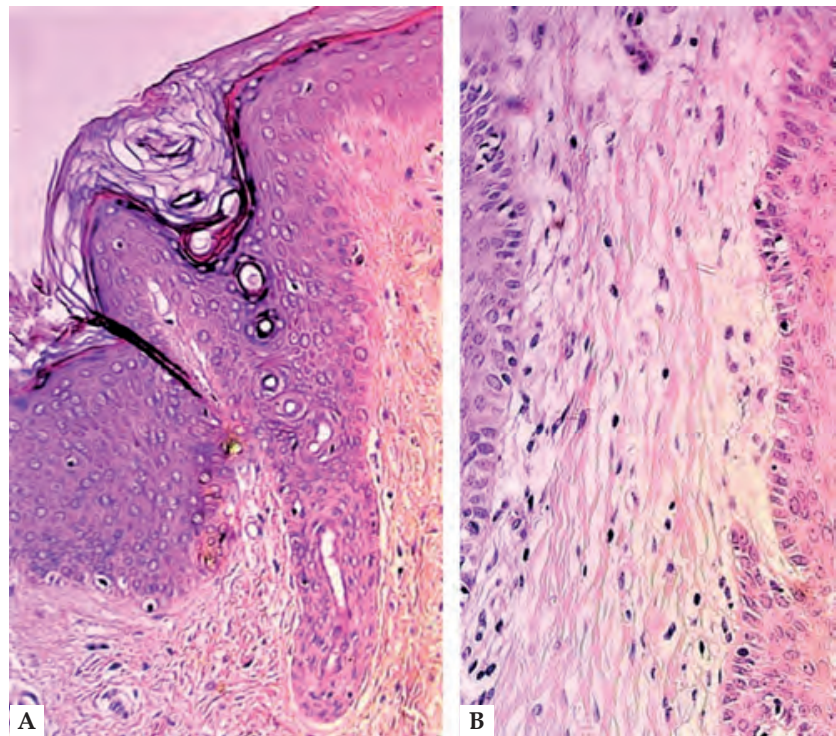

Figure 5: Fox-Fordyce Disease. A - Histological section with characteristic corneal plug and lymphohistiocytic inflammatory perifollicular infiltrate (Hematoxylin \& eosin, x20) B - Higher magnification of peri-infundibular cells with xanthomatous aspect (Hematoxylin $\&$ eosin, $x 40)$

Treatment response tends to be limited or partial; the lesions and symptoms may recur or persist. First-line treatments include topical and oral retinoids, benzoyl peroxide, topical calcineurin inhibitors, clindamycin, intralesional or topical steroids, and oral contraceptives, the latter reported with complete resolution of lesions. ${ }^{14}$ In our first case, the patient was treated with topical clindamycin, achieving partial improvement of the lesions and symptoms. In the second case, the patient was treated with combined oral contraceptives and topical hydrocortisone, achieving partial improvement of lesions and pruritus.

Alternative therapies as second-line treatment or in severe cases, such as botulinum toxin, phototherapy, electrocoagulation, copper vapor and $\mathrm{CO}_{2}$ laser, liposuction, curettage, and microwave have been described with favorable results. ${ }^{10,15}$

We have reported two cases here, both with perifollicular xanthomatosis on histology, supporting the position that this is the most specific and distinctive feature of this relatively rare disease. $\square$ 


\section{REFERENCES}

1. Boer A. Patterns histopathologic of Fox-Fordyce disease. Am J Dermatopathol. 2004;26:482-92.

2. Hurley HJ, Shelley WB. Apocrine sweat retention in man. I. Experimental production of asymptomatic form. J Invest Dermatol. 1954;22:397-404.

3. Tetzlaff MT, Evans K, DeHoratius DM, Weiss R, Cotsarelis G, Elenitsas R. Fox-Fordyce Disease Following Axillary Laser Hair Removal. Arch Dermatol. 2011:147:573-6.

4. Gurusamy L, Jegadeesan M, Jayakumar S. Fox-Fordyce disease of the vulva. Indian J Sex Transm Dis. 2016;37:65-7.

5. Ballester I, López-Ávila A, Ortiz S. Enfermedad de Fox-Fordyce con presentación clínica atípica. Actas Dermosifiliogr 2013;104:832-4.

6. Kao PH, Hsu CK, Lee JY. Clinicopathological Study of Fox-Fordyce disease. J Dermatol. 2009;36:485-90.

7. Alikhan A, Gorouhi F, Zargari 0. Fox Fordyce exacerbated by hyperhidrosis. Pediatr Dermatol. 2010;27:162-5.

8. Alés-Fernández M, Ortega-Martínez de Victoria L, García-Fernández de Villalta MJ. Lesiones axilares después de tratamiento de depilación con luz pulsada intensa. Actas Dermosifiliogr. 2015;106:61-2.
9. George A, Bhatia A, Thomas E. Fox-Fordyce disease: A report of 2 cases responding to topical clindamycin. Indian J Dermatol Venereol Leprol. 2015;81:87-8.

10. Barnhill RL, Crowson AN, Magro CM, Piepkorn MW. Dermatopathology. 3rd ed. New York: Mc Graw Hill; 2010.

11. Stashower ME, Krivda SJ, Turiansky GW. Fox-Fordyce disease: diagnosis with transverse histologic sections. J Am Acad Dermatol. 2000;42:89-91.

12. Bormate $A B \mathrm{Jr}$, Leboit PE, McCalmont TH. Perifollicular xanthomatosis as the hallmark of axillary Fox-Fordyce disease: An evaluation of histopathologic features of 7 cases. Arch Dermatol. 2008;144:1020-4.

13. Yost J, Robinson M, Meehan SA. Fox-Fordyce disease. Dermatol Online J. 2012;18:28.

14. González-Ramos J, Alonso-Pacheco ML, Goiburú-Chenú B, Mayor-lbarguren A Herranz-Pinto P. Successful treatment of refractory pruritic Fox-Fordyce disease with botulinum toxin type A. Br J Dermatol. 2016;174:458-9.

15. Taylor D, Au J, Boen M, Fox S, Aronson IK, Jacob C. A novel modality using microwave technology for the treatment of Fox-Fordyce disease (FFD). JAAD Case Rep. 2015;2:1-3.

\section{AUTHORS CONTRIBUTION}

María Elisa Vega-Memije

(iD) ORCID 0000-0001-7985-118X

Approval of the final version of the manuscript; Conception and planning if the study, Elaboration and writing of the manuscript; Obtaining, analyzing and interpreting the data; Effective participation in research orientation; Intellectual participation in propaedeutic and/or therapeutic conduct of cases studied; Critical review of the literature; Critical review of the manuscript

Diego Olin Pérez-Rojas

ORCID 0000-0003-3459-9309

Approval of the final version of the manuscript; Conception and planning if the study; Elaboration and writing of the manuscript; Obtaining, analyzing and interpreting the data; Effective participation in research orientation; Critical review of the literature; Critical review of the manuscript

\section{Leticia Boeta-Ángeles \\ ORCID 0000-0002-9794-0140}

Approval of the final version of the manuscript; Conception and planning if the study; Obtaining, analyzing and interpreting the data; Intellectual participation in propaedeutic and/or therapeutic conduct of cases studied

Patricia Valdés-Landrum ～～～ORCID 0000-0001-6957-1897

Approval of the final version of the manuscript; Conception and planning if the study; Obtaining, analyzing and interpreting the data; Intellectual participation in propaedeutic and/or therapeutic conduct of cases studied

How to cite this article: Vega-Memije ME, Perez-Rojas DO, Boeta-Ángeles L, Valdés-Landrum P. Fox-Fordyce disease: report of two cases with perifollicular xanthomatosis on histological image. An Bras Dermatol. 2018;93(4):562-5 